\title{
Investigation of the Vegetable Logistics Operation Mode and Study on Optimization of Operation System
}

\author{
Tingting Yang ${ }^{1, a^{*}}$, Mingwang Dong ${ }^{1, b}$ and Haili Lv ${ }^{1, c}$ \\ ${ }^{1}$ Logistics Engineering Wuhan University of Technology, Hubei, Wuhan \\ a373622800@qq.com, bwulin@whut.edu.cn, cvital@whut.edu.cn
}

\section{Keywords: Vegetables; Logistics Mode; Operation Optimization}

Abstract. This paper analyzes the status of China's vegetable, combined with vegetables logistics concept, characteristics and operational requirements, describe the vegetables logistics body according to the different circulation during the logistics mode. Then, discuss the existing logistics mode and analysis the advantages and disadvantages of them. Finally, analyses the operation situation of vegetable logistics of various areas, points out the factors that affect the existing vegetables logistics operation mode and its deficiency in development. Put forward the suggestion and scheme to solve the problems targeted on the logistics body, logistics links, mode choice

\section{Introduction}

Vegetables play a very important role in agricultural production and the lives of the residents in China, and China is the largest vegetable production country in the world. With the increasing development of social economy, people's living standards and environmental awareness and deepen understanding of the concept of green consumption, people put more and more attention on high quality and safety of agricultural products [1]. Nowadays, more and more domestic and foreign scholars put attention on many aspects of vegetable logistics, but the research on the selection and optimization of the regional logistics mode are still at an initial stage. Compared with foreign countries, the research of our country is relatively backward. This paper optimizes the selection of vegetable logistics mode, promotes the flexibility of market information, gradually reduces the traditional scattered smallholder production mode, reduces the loss and cost of vegetables in circulation, improve the quality of vegetables reaches the final consumer.

\section{Regional vegetable logistics}

The concept and characteristics of regional logistics. Vegetables are perishable products, not only reduce the value of the product, but also affect the interests of vegetables operators' interests. The corrosion rate of the vegetables in the course of circulation is as high as $20 \%$ 30\%, and other loss, the loss rate is about 30\% 50\%. Vegetable logistics is generally considered as the circulation of vegetables from the producer to the consumer, the main process is vegetable production, processing, transportation, loading and unloading, storage, distribution and information transmission, release the value added and organizational goals.[2]

Vegetable logistics chain. Vegetable logistics chain is a physical motion chain form vegetable products to consumer, also is a dynamic network chain composed of vegetable producers (farmers), cooperative organizations, trafficking business, storage and transport enterprises, wholesale, processing enterprises, distribution center and related enterprises constitute [3]. China's current vegetable logistics subject included in the fresh vegetable producers, traders sell households, farmers, cooperative organization, processing enterprises and various properties of middlemen and various types of retail terminal.

Because of the characteristic of vegetables, vegetable logistics has a different from the general logistics: (1) subject to natural conditions, with seasonality and periodicity; (2) the transport requirements are high, and the logistics process is invested with the special purpose of the fund; (3) the market power is unbalanced, and has the large market uncertainty; (4) huge traffic, high proportion of logistics costs; (5) the risk of transportation of vegetables is large.. Therefore, we must achieve the low 
cost, high efficiency of logistics operation, which need to overcome the above all kinds of objective market factors and natural factors, undoubtedly bring logistics difficulty.

Current model of Regional vegetable logistics. Our country vegetable planting is relatively dispersed, it is difficult to form a fixed distribution center, at present mainly rely on the main cultivation region to form the wholesale market, and gradually spread out[4]. Different regions for the actual situation have different logistics mode. According to different combinations, our country has the following logistics modes.

Vegetable logistics mode dominated by vegetable wholesale market. Origin wholesale logistics mode summarizes the current bulk logistics organization form among domestic production and sales, constitute the main part of the existing fresh vegetable logistics system. The dominant leader of this model is the agricultural product wholesale center; the participant is the agricultural product producer, the distributor and the retailer.

This is a traditional and typical vegetable logistics mode, can directly docking with the supermarket and farmer's market. But there are also some problems in the physical model, the organization of the main body is huge, but the scale is small, the contract is not obvious, the technical level is low, the lack of value-added processing and logistics services, especially performance in the cold chain logistics, information technology and so on.

Vegetable logistics mode dominated by the agricultural cooperative organization and Cooperative. This model including the small farmers, grassroots agricultural cooperative organizations, cooperatives, logistics service suppliers, wholesalers, retailers and consumers, vegetable. In this mode, the relationship between the farmer and the cooperative organization is closer. Professional cooperatives and their partners cooperate by order. This kind of vegetable planting can reduce the blindness of the traditional farmers economy, and greatly reduce the risk of the blind investment, and also solve the problem of the vegetable market.

A wholesale market is the professional cooperatives vegetables selling places. Farmers rely on the professional cooperatives, sale the vegetables to the wholesale market, expand the ways of professional cooperatives vegetable sales. For farmers, the professional cooperatives know demand and prices of vegetable market well, thus can promote the discourse power and competitiveness.

Vegetable logistics mode dominated by the professional distribution enterprise. Specialized distribution enterprise is the intermediate organization which specializes in the storage and transportation of agricultural products and the circulation process. They are not engaged in the production and marketing of any direct agricultural product, but take on the main function of the logistics of agricultural products. But it should be pointed out that, due to the third party logistics of agricultural products just in the initial stage, the management level, information system construction and data sharing, network construction, professional services also faces many problems. This model is generally existed in the cities of the more developed economy.Among them, as the core of the third party logistics enterprises or the third party logistics alliance, form strategic partnership with farmers market, community farms, and supermarkets. Consumers can also benefit from this quick logistics mode.

Direct link between farmers and supermarkets. The mode of direct link between farmers and supermarkets take the supermarket as the core. It means chain supermarket enterprise establish stable and continuous purchasing relationship with farmers, agricultural cooperatives and economic people. Or chain supermarket companies directly rent the land in the countryside and grow agricultural products for the terminal market sale.

\section{Analysis of abroad typical vegetable operation modes}

The vegetables in the developed countries are relatively few, and the research on the logistics of vegetables is generally reflected in the logistics of agricultural products. Developed countries attach great importance to the logistics of agricultural products, has a strong economic strength, advanced logistics facilities, sound infrastructure, and high information level. After a long exploration, influenced 
by various factors such as social system, economic development level, agricultural production level and so on., many developed countries have formed the advanced and characteristic agricultural logistics operation mode.

American vegetable operation mode and its reference significance. The circulation principle of fresh agricultural products in America is voluntary trading, fair competition and market pricing. Agricultural products in the market mainly performance for four kinds of logistics channel to supply consumer groups. (1) the farmer direct selling to the wholesale market or origin set with market. (2) the farmer sales directly to the retail terminal (chain supermarkets, retail enterprises) in accordance with the purchase and sale contract; (3) the farmer directly selling products at a farmers' market; (4) farmers through distribution center graded packaging exports overseas markets.

The mode of direct marketing reduce the circulation link from agricultural products to the final consumer, can greatly save the time of the vegetables circulation, guarantee the freshness of vegetables. According to statistics, its fresh agricultural products accounted for $56 \%$ of the market share of retail sales, which is usually about $9.5 \%$ of total sales. American transportation system and other infrastructure is very developed, not only realize the local conditions of multimodal transport mode, but also smooth highway, railway, water transport and other transport Agricultural products logistics, warehousing, transportation and other infrastructure is also very perfect, provides the basis for the effective and timely distribution of vegetables logistics. The degree of information of American vegetable logistics is very high, the establishment of a logistics socialized service system is perfect. Any link of any demand will be met. In general, the logistics mode of the United States shows the characteristics of "big production and large circulation".

Logistics operation mode of agricultural products in Japan and its reference significance. East Asia mode take agricultural products logistics operation mode of Japan, South Korea and China Taiwan as the representative, take the wholesale market as the main channel, characterized by auction system. Japan is the most typical countries, East Asia Logistics Model in with a strong demonstration effect. In particular, the natural conditions of similar countries and regions and even parts of the European countries take East Asia mode as a model for learning.

As a result of more people and less land and limited natural resources, it's difficult for Japan to achieve the organization of agricultural product logistics, intensive and scale. In order to solve the small and decentralized production scale, reduce the risk and transaction costs of the farmers entering the market alone, they pay much attention to the function of agricultural society, and form the vegetable logistics mode characterized which called "island mode". Through the establishment of the core of the wholesale market for agricultural logistics system, effectively protect the city's supply of agricultural products. Through the participation of the government, the wholesale market can only conduct wholesale business. At the same time, there are strict conditions for the wholesale operators involved in the market, non wholesale traders are allowed to trade directly and ensure the smooth circulation of agricultural products. In addition, dependent on wholesale market related social oriented service system including brokers and other intermediaries, providing goods transportation, information consulting, lease transfer business, thereby providing the efficiency of the whole logistics system.

The logistics mode of EU agricultural products and its reference significance. The development of the logistics industry of the European agricultural products is one of the most typical in Holland. One of the reasons is that it has a very advantageous geographical advantage - located in the center of Europe. Holland made full use of the favorable conditions to develop agricultural products and food logistics industry, and distributed high-quality agricultural products all over the world. It can be said that it is the distribution center of Europe in this sense. Holland is the world's dairy country, vegetable and flower kingdom, The export of agricultural products is third in the world. Data show that: The ratio of the output value of agricultural products in Holland and the output value of agricultural products is $1: 4$. However, the ratio of our country is only $1: 1$; The loss rate of vegetables and fruits in Holland is 5\%, While our country is as high as $25 \%$, annual loss about eight million tons. Holland agricultural products logistics industry has developed air transport network. The logistics chain of agricultural products is shorten, realize the logistics value, and the degree of 
informationization is high, pay attention to the development of frozen storage, frozen industry is very developed.

Holland established the mature electronic virtual fresh vegetable logistics system, connect fresh vegetables suppliers, manufacturers, wholesalers, retailers and farmers through the network, form fresh vegetables logistics chain, have good transportation system, actively develop fresh vegetable cold chain logistics. The cooperative organization of Holland is very developed. Some cooperation organizations even have their own sales network abroad, they put most of the fresh vegetables tighter through the cooperative organization to the wholesale market, in order to open the auction and other sales to foreign markets.

\section{Optimization regional vegetable logistics model}

Compared with the foreign advanced vegetable logistics mode, the regional vegetable logistics mode in China mainly has the following questions: (1) the degree of organization of the main body of the logistics is relatively low; (2) logistics technology is backward, logistics costs are higher; (3) the degree of information is low; (4) the degree of standardization of vegetables logistics is low. The paper puts forward the following optimization suggestions and measures according to the present situation of vegetable logistics in China.

Promote the organization degree of Farmers and other logistics main body. The new vegetable circulation mode should pay attention to the role of agricultural cooperative in the circulation of vegetables, and exert the function of agricultural cooperative. Farmers form the agricultural cooperative, and reach the large-scale production level, thus promote the organization degree of farmers. Vegetable Wholesale Center encourage vegetable growers set up specialized cooperatives, organize the decentralized farmers, unified market and price, change the wholesale market trading conditions, can effectively prevent market on vegetables wholesale of vicious competition.

Actively promote the development of the third party logistics. The introduction of the third party logistics is the result of the specialization division of labor, it can give full play to the effect of scale economy, reduce the investment of special assets of the supply and demand, can effectively reduce the cost of circulation.

Because the third party logistics has the specialized logistics management ability, familiar with the characteristics of logistics activities in all aspects, master of advanced logistics technology and facilities and equipment, can provide differentiation, targeted services for customers according to the different needs of customers. Except the traditional functional business, such as the goods picking, handling, transportation, warehousing, customs clearance and distribution processing, the service content also include freight negotiation, freight payment, transportation, inventory management report and other information, development logistics strategy and application logistics management software, which can meet the different industries of personalized, diversified logistics needs.

Shorten the circulation and reduce the time of circulation. Shorten the circulation of the vegetables logistics can reduce the loss cost of intermediate business, facilitate the government to monitor and adjust the vegetable circulation enterprises, which can make the market supply and demand information in the circulation system more rapid and effective, so that the farmers get more market information, can better control the market.

First, strengthen cold storage facilities of agricultural products logistics, such as the supermarkets, base, cooperatives and other important node. Accelerate the layout of a number of fresh agricultural products at the center of the low temperature distribution and processing center in large and medium cities. Focus on strengthening the construction of agricultural special transport vehicles such as container and refrigerated truck, as well as the construction of agricultural product storage facilities such as special warehouse, special warehouse, low temperature, cold storage, warehouse, etc.. Second, improve the temperature control facilities of agricultural products processing, construct the agricultural products pre cooling facilities, equip with energy saving, environmental protection of the 
long and short of cold chain transport vehicles, to promote the full temperature monitoring equipment; Promote fresh agricultural products quality grading, packaging standardization.

Strengthen the cold chain docking system of Upstream and downstream enterprises; Strengthen the temperature monitoring and traceability system of the relevant enterprises, protect the quality and safety of agricultural products in the production and circulation of all links. This mode are easier to achieve in economy developed cities, but does not apply to the relatively backward areas.

\section{Summary}

Based on the theoretical results of fresh vegetable logistics and international fresh vegetable logistics research, this paper analyze the mature vegetable logistics mode foreign countries such as the United States, Japan and other developed countries, and draw lessons from it. At the same time, compared with the advanced vegetable logistics mode, find out the advantages and disadvantages of vegetable logistics in China, and proposed solutions and methods according to these questions.

\section{References}

[1] Hongqi Wang. Analysis about Condition of Country's Agricultural Products Logistics Operation Mode [J]. Logistics Sci-Tech, 2013, 36(3):101-103.

[2] Srimanee, Y.,J.K. Routray. The fruit and vegetable marketing chains in Thailand: policy impacts and implications[J]. International Journal of Retail \& Distribution Management, 2012. 40(9): 656-675.

[3] Yunliang Wu. Present Situation and Optimal Measures of Vegetable Logistics Chain in China[J]. Resource Development \$ Market, 2007. 23(4): 326-328.

[4] Jing Wu. Vegetable Distribution and Modern Logistics [J]. Logistics technology, 2006(5): 6-8. 